\title{
A Cosmetically Acceptable Dye Product to Improve Detection of Head Louse Eggs and Nits
}

\author{
Elizabeth R Brunton ${ }^{1,2,+}$, Mark N Burgess ${ }^{2,+}$, Ian P Whelan ${ }^{1,3}$ and Ian F Burgess $1,2, * \mathbb{D}$ \\ 1 EctoMedica Limited, Cambridge CB25 9AU, UK; info@ectomedica.com \\ 2 Insect Research \& Development Limited, Cambridge CB25 9AU, UK; info@insectresearch.com \\ 3 Avisius Research Limited, Coventry CV3 4FJ, UK; avisiusresearch@gmail.com \\ * Correspondence: ian@insectresearch.com; Tel.: +44-1223-813696 \\ + Equal contributors.
}

Received: 4 March 2020; Accepted: 22 March 2020; Published: 24 March 2020

\begin{abstract}
Removing head louse eggshells and nits after a successful pediculicide treatment is often made more difficult because it is not easy to see them all amongst the hairs. Therefore, a treatment that makes louse eggs more visible potentially makes the task of removal easier and reduces the risk that children would be sent home from school or over-treated. This project involved the development of a hair treatment gel concept that was easy to apply, wash out, and that stained louse eggs and nits but without staining the hair and skin. A series of food-grade dyes were evaluated for their ability to stain the eggshells, and various copolymer-based rheology modifiers were tested for dye compatibility and stability. Several dyes were rejected because either they failed to stain louse eggshells or else stained skin too easily. Two dyes, Patent Blue and Ponceau 4R, were eventually selected for different product developments, one specifically for post-treatment nit removal and the other for pre-treatment diagnosis. In clinical field studies, both were found to make the treated eggshells contrast sufficiently with the hair to enable identification of persistent nits. Use of a nit stain product can enable easier detection of louse eggs and nits, thus facilitating the removal process and reducing the risk that persistent eggshells could be mistaken for signs of a continuing infestation.
\end{abstract}

Keywords: combing; polymeric hair gel; food dye; hair care; nit removal; diagnosis; "no-nit" policy

\section{Introduction}

Treatment of head louse infestation is relatively straight forward, within certain limitations. The majority of treatment methods require an application of a topical formulation to the hair and scalp for a set period of time, followed by washing to remove it. This approach is achievable by most caregivers provided the preparation used is effective to kill lice and their eggs, not affected by resistance to the active ingredient, and is reasonably easy to apply. History has shown that some products are more likely to be effective than others [1-3], but with adequate dosing using an effective product, an infestation can be eliminated without too much difficulty.

Even after an infestation has been cured, a cosmetic problem remains. The eggshells (nits), whether hatched or not, remain attached to the hair by the robust insoluble glue-like substance secreted by the female louse when laying them close to the scalp. The presence of these eggshells is a source of embarrassment for many children, especially older girls who wish to have their hair tied up or otherwise groomed in a fashionable manner. Over the years, numerous combing devices have been developed to physically remove these eggshells, with varying degrees of efficiency [4-6]. All nit-combs are claimed by their makers to remove all intact or hatched eggs (nits), although the claims are often hard to substantiate because many are made from materials of insufficient rigidity to pull the tightly 
fixed eggs and nits from the hair or have teeth too far apart to prevent the eggshells slipping between them [4-6].

Various entrepreneurs have developed chemical products claimed to loosen the grip of the glue-like substance, although so far, only one has proved effective [7], and the majority are generally formulated based on false premises and a complete misunderstanding of the chemical nature of both the eggshell and its fixative [8,9].

Although hatched nits can be relatively easy to see because they reflect light and appear white in color, or even blue-white if viewed with near ultraviolet light, eggshells with embryos, particularly when close to the scalp, are difficult to see and are often only detected some weeks after elimination of infestation as they grow out with the hairs. A detection aid to make louse eggs and nits stand out from their background would make a significant improvement to the process of nit removal.

Before the start of this project, a single commercial product was available for highlighting louse eggshells to facilitate detection. The product, Neon NitsßLice Egg Locator Spray (Neon Nits, LLC, Dayton, TN, USA), a pressurized aerosol containing a fluorescent dye substance in a solvent/polymer base, produces a relatively messy and sticky coating that requires brushing and washing from the hair after use to prevent staining of light-colored hair (Figure 1) [10].

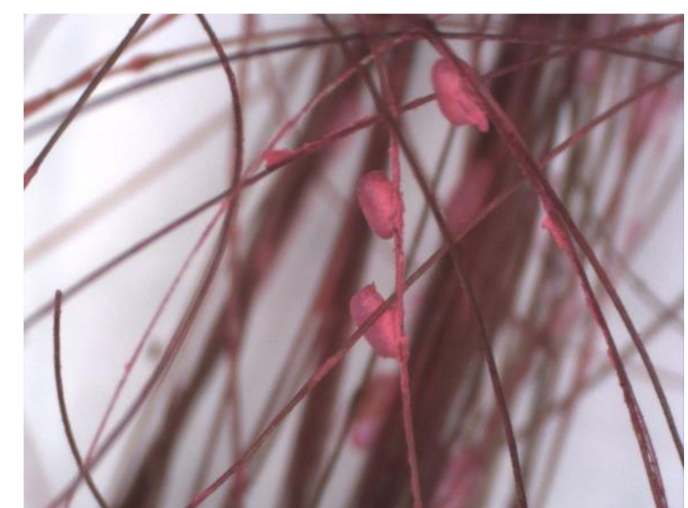

(a)

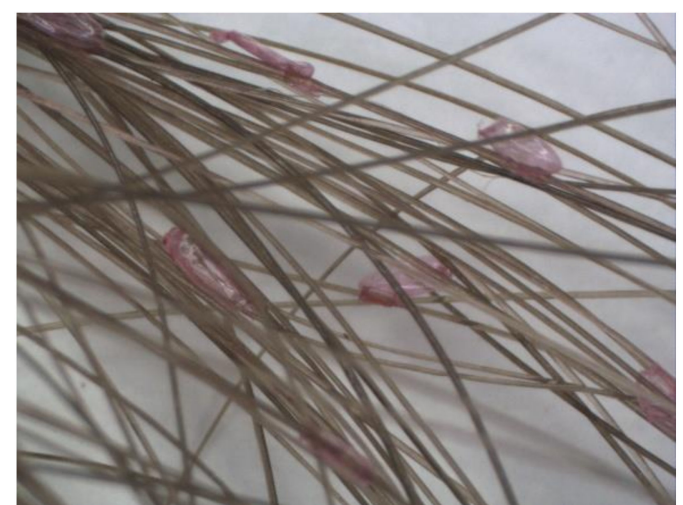

(b)

Figure 1. Nits stained with Neon Nits®Lice Egg Locator Spray. (a) Nits coated with pink spray residue immediately after application; (b) Treated nits after vigorous brushing and washing to remove spray powder debris.

The aim of this project was to develop a simple-to-apply, wash-out preparation that would stain louse eggshells without staining the hair or skin for use in Spain, where it is considered a cosmetic by regulators because it has no direct effect on infestations. At that time, all products in Spain that had a direct effect, i.e., killed lice or their eggs, were listed under the category of "pediculicide", a listing not found in other European Union countries, and which exempted this type of staining preparation. Elsewhere in Europe, a different viewpoint exists, and an approach made to the Medicines and Healthcare products Regulatory Agency (MHRA) in the United Kingdom resulted in a categorical response that, when using a nit stain of this type, it would not be possible to be certain that there were no viable eggs remaining on the head, resulting in a therapeutic effect so, "On this basis therefore, MHRA [was] of the opinion that such a product should be CE marked as an accessory to the nit comb as a medical device intended for the identification and removal of nits". The formulation concept and development process were initially presented as a conference poster [11].

\section{Materials and Methods}

\subsection{Louse Egg Colorants}

We investigated various dye substances, with an emphasis on safety and biocompatibility. The first stage was to identify food-grade dyes that did not stain hair but were capable of staining 
louse eggshells, composed of a chitin-like complex carbohydrate [12], and the glue-like fixative that is primarily proteinaceous [12,13]. Prior art suggested that some dyes from the groups, including triphenylmethanes, xanthenes, anthraquinones, and pyrazolones, could be used [10,12]. In order to avoid any competitive issues, we investigated the activity of alternative water-soluble azo dyes and obtained coal tar dyes as well as some pigments of natural origin (Town End (Leeds) Plc, Leeds, UK). Simple aqueous solutions of each dye were prepared at $1.0 \%$ and $0.1 \% w / v$ and tested against louse eggshells by immersing different tufts of hair bearing several intact eggs or hatched eggs (nits) in each solution for either 30 or $60 \mathrm{~s}$.

For this comparison, the eggs used were hatched and unhatched louse eggs from a laboratory-reared colony of human body/clothing lice, Pediculus humanus humanus, laid on hair of different colors. Treated eggshells and glue fixative were examined by stereomicroscope to determine whether any staining had occurred. If the eggshells showed an acceptable level of stain, they were washed to test for color-fastness and the ability to wash the stain out. Staining of hair was evaluated macroscopically in good natural light, followed by shampoo washing to check that color residues could be removed from the hair.

A literature search indicated potential activity of 14 dyes from six chemical families, with a possibility to evaluate up to 30 other compounds should none of the first cohort prove appropriate.

\subsection{Gel Vehicle}

We identified a water-based cosmetic gel-like dosage form as a practical method for application and simple removal by hair washing. Many compounds used in the manufacture of traditional cosmetic gels, such as the acrylic acid-polyalkenyl polyether derivatives (carbomers), require multi-step manufacture and $\mathrm{pH}$ adjustment. The aim was to find a gelling compound that could be formulated using a single step or two-step manufacturing process and that was not only tolerant of the incorporation of dyestuff but also did not reduce the dye bioavailability by locking it up within the polymer matrix.

There are numerous cosmetic products that provide a higher viscosity to aqueous mixtures, including thickeners, polymeric gelling agents, and rheology modifiers. Several of these could be used in the test system, especially those that exhibit thixotropic characteristics. However, we limited our search to one group of compounds, those based on acrylates that offered one-step mixing and forming.

\subsection{Formulation Development}

The formulation development program compared a standard carbopol gelling agent with various acrylate gels using different concentrations of dye substance and different preservative systems. Gels were tested for their ability to stain louse eggs and the glue fixative, physical stability at high and low storage temperatures, and color stability in storage and on light exposure. We found that different dye substances exerted different effects on the rheology characteristics of gels according to the proportions of dye and gelling agent in the mixture. The overall screening process quickly eliminated some options due to the incompatibility of components, physical breakdown of the gelling system when the dye was added, loss of bioavailability of the dye in the gel, and even loss of dye color in some mixes. In addition, suitable preservatives were screened for compatibility with the overall gel systems.

For this concept formulation, we identified a new multifunctional, cationic copolymer-based rheology modifier, originally developed for hair styling preparations, as a suitable gel-forming vehicle. The compound, a cross-linked copolymer of vinylpyrrolidone, vinylimidazol, 3-methyl-1vinylimidazolium chloride, and methacrylic acid (CAS 935522-29-5) (BASF, Ludwigshafen, Germany) appeared to satisfy all the necessary requirements for this type of novel formulation. This compound was easily dispersed in water and exhibited rapid swell characteristics using simple agitation without heating. A major advantage over many other gels was its tolerance of lower $\mathrm{pH}$ levels, especially at a physiological $\mathrm{pH}$ of 5-6. Alternative gelling agents included glyceryl betaine/polyacrylic acid and esters (CAS: 942044-86-2) and sodium polyacrylate with glycerol (CAS: 56-81-5, 9003-04-7). 
Irrespective of the concentration of the gel base or of the dye, addition of the colorant to the gel-increased fluidity and required careful monitoring during mixing. In conjunction, the timing of adding the dye during the mixing process altered the dyeing characteristics of the final gel, with reduced staining if added too early or difficulty in obtaining homogeneity if the dye was too late in the mixing process.

\subsection{Field Evaluation}

The effectiveness of the gel to stain louse eggs and nits was confirmed in field studies in which an investigator applied the product to the hair of children with active or suspected head louse infestations. Prospective participants were provided with an information leaflet describing the purpose of the study, and written informed consent was obtained from a parent or guardian prior to the treatment. In each case, the investigator first combed the hair with a styling comb then spread the gel through the hair down to scalp level using a combination of the applicator of the product container, massaging with their fingers, and/or using a styling comb. Systematic application of the gel started at the nape of the neck, with the head leaning forward, and working towards the front of the head, treating the hair on the temples last. This sequence was adopted in case there was any skin staining, based on the principle that the skin on the back of the scalp at or around the nape of the neck is not normally visible because it is covered by a thick layer of hair, and so, any temporary staining would not be unsightly.

After application, the gel was left in situ for $2 \mathrm{~min}$, followed by rinsing out with water. The hair was then towel-dried and combed with a styling comb to remove tangles, after which it was combed using a nit comb. The louse eggs and eggshells were then transferred from the comb to the case record to check for evenness and distribution of staining. Any active cases of head louse infestation, identified by finding live lice during the combing process, were treated using an appropriate commercial pediculicide.

\section{Results}

\subsection{Louse Egg Staining in the Laboratory}

Of the 14 dyes evaluated using simple aqueous solutions, some had no capacity to stain either the eggshell or the glue-like substance, whereas others stained both, with some showing variability according to concentration (Figure 2 and Table 1). In general, intact (unhatched) eggshells were more difficult to stain than those that had hatched. There was some question as to whether dyes from the so-called "Southampton 6" would be suitable, [14], but in practice, with the exception of Sunset Yellow and Ponceau, they showed little or no activity (Table 1), so their elimination did not deplete the pool of possible dyestuffs that could be used in a product.

When incorporated into a gel, the most consistent results for the intensity of stain on eggs and glue, but without staining of hair or skin, were obtained using $0.05 \%$ Patent Blue in a preserved $1.0 \%$ gel base. The gelling agent improved the bioavailability of the dye for the eggshell materials making a lower concentration of dye necessary to avoid skin staining. This preparation gave stable staining of eggs and nits at $\mathrm{pH} 5$, with a slight fade at $\mathrm{pH}$ readings of 3,7 , and 8 . Once the eggs were stained, the dye was not light stable, so it naturally faded with time if not washed out.

Most prepared gels stained the louse eggshell; some also stained the fixative "glue", whereas others either produced a "two-toned" effect where either the fixative or the eggshell was not stained. Nits stained more deeply than intact eggs whereas the chorionic membrane, left behind when the louse nymph emerged, in some cases stained more intensely than the eggshells. 
One concern about using dye-based products in the bathroom was whether there was a risk that spillage or wash out of the gel would color or stain bathroom fixtures such as white baths and washbasins, tiling grout, silicone sealants, as well as towels and other fabrics. An extensive laboratory investigation showed that, provided any spilt gel was removed quickly, washed with a detergent solution, and rinsed within $1 \mathrm{~h}$, no lingering staining or color persisted on any of the tested substrates. However, if the spillage was left in contact with tiling grout for $24 \mathrm{~h}$, removal was difficult, leaving some traces of color on the porous grout surface.
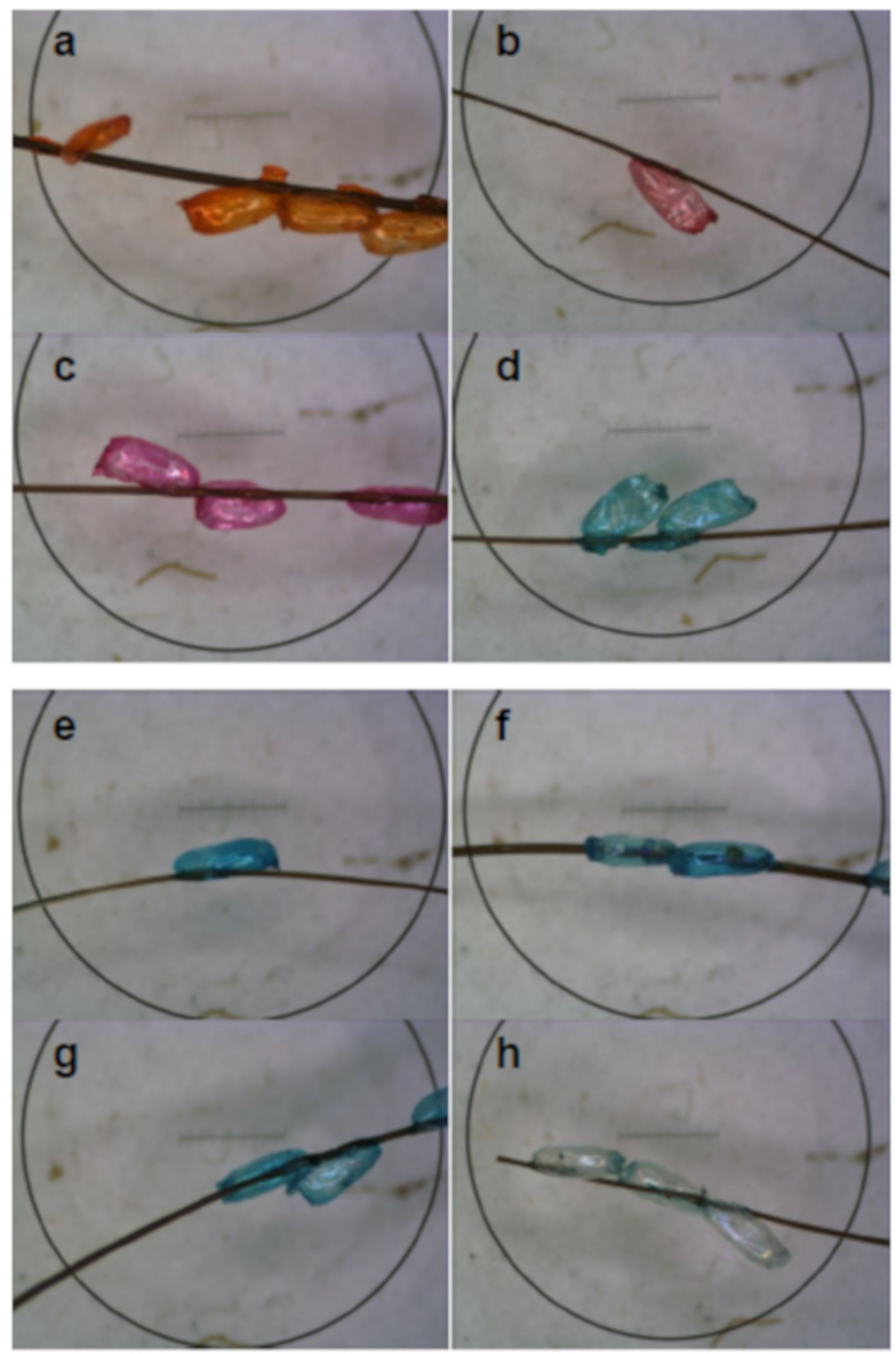

Figure 2. Staining effect of different dyes on hatched eggshells (nits). (a) = Sunset Yellow 1.0\%, $(\mathbf{b})=$ Ponceau 4R 1.0\%, (c) = Erythrosine 0.1\%, (d) = Green S 0.1\%, (e) = Patent Blue 1.0\%, (f) = Brilliant Blue $1.0 \%,(\mathrm{~g})=$ Patent Blue 0.1\%, (h) = Brilliant Blue 0.1\%. 
Table 1. Staining effects of various dyes applied to intact and hatched human louse eggshells.

\begin{tabular}{|c|c|c|c|c|c|c|c|}
\hline \multirow[t]{3}{*}{ Dye Name } & \multirow[t]{3}{*}{ E Number } & \multirow{3}{*}{$\begin{array}{l}\text { Color } \\
\text { Index }\end{array}$} & \multirow[t]{3}{*}{ Chemical Family } & \multirow[t]{3}{*}{ ConcentratIon } & \multicolumn{3}{|c|}{ Staining Level/Exposure Time } \\
\hline & & & & & \multicolumn{2}{|c|}{30 seconds } & \multirow{2}{*}{$\begin{array}{l}60 \text { seconds } \\
\text { Unhatched }\end{array}$} \\
\hline & & & & & Hatched & Unhatched & \\
\hline \multirow[t]{2}{*}{ Tartrazine } & E102 & CI 19140 & Monoazo & $0.1 \%$ & - & - & ND \\
\hline & & & & $1.0 \%$ & - & - & ND \\
\hline \multirow[t]{2}{*}{$\begin{array}{l}\text { Quinoline } \\
\text { Yellow }\end{array}$} & E104 & CI 47005 & Quinoline & $0.1 \%$ & + & \pm & $+/ \pm$ \\
\hline & & & & $1.0 \%$ & + & \pm & ND \\
\hline \multirow[t]{2}{*}{ Sunset Yellow } & E110 & CI 15985 & Monoazo & $0.1 \%$ & - & $+/ \pm$ & ND \\
\hline & & & & $1.0 \%$ & $+/ \pm$ & + & + \\
\hline \multirow[t]{2}{*}{ Cochineal } & E120 & CI 75470 & Indigoid & $0.1 \%$ & - & - & ND \\
\hline & & & & $1.0 \%$ & \pm & - & ND \\
\hline \multirow[t]{2}{*}{ Carmoisine } & E122 & CI 14720 & Monoazo & $0.1 \%$ & - & - & ND \\
\hline & & & & $1.0 \%$ & - & - & ND \\
\hline \multirow[t]{2}{*}{ Amaranth } & E123 & CI 16185 & Monoazo & $0.1 \%$ & - & - & ND \\
\hline & & & & $1.0 \%$ & +++ & + & +++ \\
\hline \multirow[t]{2}{*}{ Ponceau 4R } & E124 & CI 27195 & Monoazo & $0.1 \%$ & + & ++ & $+/ \pm$ \\
\hline & & & & $1.0 \%$ & ++ & + & ND \\
\hline \multirow[t]{2}{*}{ Erythrosine } & E127 & CI 45430 & Xanthene & $0.1 \%$ & ++ & ++ & ++ \\
\hline & & & & $1.0 \%$ & ++ & +++ & +++ \\
\hline \multirow[t]{2}{*}{ Allura Red } & E129 & CI 16035 & Monoazo & $0.1 \%$ & - & - & + \\
\hline & & & & $1.0 \%$ & - & + & ND \\
\hline \multirow[t]{2}{*}{ Patent Blue V } & E131 & CI 42051 & Triarylmethane & $0.1 \%$ & + & + & +++ \\
\hline & & & & $1.0 \%$ & ++ & +++ & +++ \\
\hline \multirow[t]{2}{*}{ Indigo Carmine } & E132 & CI 73015 & Indigoid & $0.1 \%$ & + & \pm & ND \\
\hline & & & & $1.0 \%$ & + & ++ & +++ \\
\hline \multirow[t]{2}{*}{$\begin{array}{c}\text { Brilliant Blue } \\
\text { FCF }\end{array}$} & E133 & CI 42090 & Triarylmethane & $0.1 \%$ & \pm & + & +++ \\
\hline & & & & $1.0 \%$ & + & ++ & ++ \\
\hline \multirow[t]{2}{*}{ Green S } & E142 & CI 44090 & Triarylmethane & $0.1 \%$ & +++ & + & ND \\
\hline & & & & $1.0 \%$ & +++ & +++ & +++ \\
\hline \multirow[t]{2}{*}{ Brown HT } & E155 & CI 20285 & Disazo & $0.1 \%$ & - & - & ND \\
\hline & & & & $1.0 \%$ & - & - & ND \\
\hline
\end{tabular}

Key to intensity of stains: - No staining, \pm Slight staining, +/ \pm Two-tone stain, + Even stain, ++ Good stain, +++ Strong stain, ND = not done.

Two class I medical device products were developed using the technology. The first, originally based on Patent Blue 0.05\% (Apaisyl@Détect Lentes, Merck Médication Familiale, Dijon, France), was launched in 2012 but was reformulated one year later because the gelling agent was withdrawn by its manufacturer. In parallel, the dye was also changed to Brilliant Blue $0.05 \%$ to improve skin compatibility, although this did reduce the intensity of eggshell staining (Figure 3a). The intensity was further reduced if the product was used following treatment with oily or silicone-based products (Figure 3b). A second product, primarily designed to detect an infestation at an early stage or when caregivers experience difficulty by not being able to find lice (Paranix Eggs Locator Gel, Omega Pharma N.V., Nazareth, Belgium), was launched in 2016 and used the red dye Ponceau 4R 0.02\% in a sodium polyacrylate/glycerol gel base. 


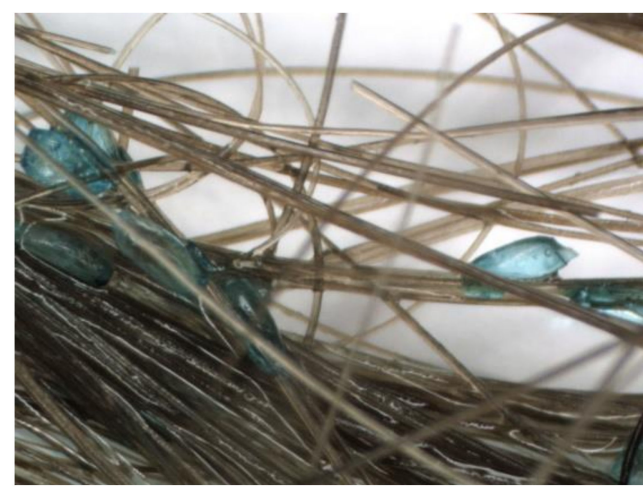

(a)

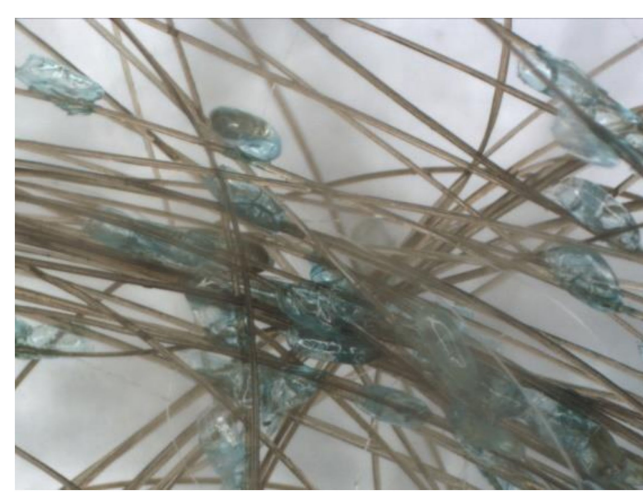

(b)

Figure 3. Staining of eggshells using the $0.5 \%$ Patent Blue gel (Apaisyl@Détect Lentes). (a) Nits on clean hair when the gel was applied; (b) Nits on hair previously treated using a silicone-based head louse elimination product, from which residues of silicone oil remained on the hair after shampooing.

\subsection{Field Studies}

Prior to marketing, the Apaisylßproduct, which was registered in France as a medical device, was tested on 31 participants by an independent consultant dermatologist at the Centre International de Développement Clinique on the island of Mauritius in June 2013. Ethical approval for the study was overseen by a private ethics committee (Apollo Bramwell Hospital, Mauritius) because the government committee was deemed "not competent for consideration of medical devices" [15]. The aim of this investigation was to confirm the product safety and effectiveness of the dyeing effect in vivo. The study found that the product could be applied in 3 minutes or less on all but four people from a cohort with short to medium length hair. Following the 2-min exposure period, only two participants exhibited any sign of staining of the skin after rinsing, one of whom had skin phototype IV, and the other, phototype VI. Therefore, staining of skin was not specifically related to skin color, and none of the lighter-skinned participants were observed to have dye on the skin. On the partitioned off section of hair on the side of the subject's head that was selected for counting, it was found that the treatment increased the detection rate for identifiable eggshells from a mean of $16.9 \pm 2.0$ to a mean of $18.4 \pm 2.2$. This difference was estimated to be significant $(p=0.006)$ by the statistician and demonstrated that the product could make about $9 \%$ more eggshells visible than could be readily detected without the dye [15].

The Paranix product was tested in a study conducted in and around Cambridge, UK, by the Medical Entomology Centre. For this study of a CE-marked medical device, used within its intended purpose, there was no requirement or procedure in the United Kingdom at the time the study was conducted, to seek approval from an ethics committee or to notify the Medicines and Healthcare products Regulatory Agency (see http://www.hra-decisiontools.org.uk/ethics/). Participants had all taken part in previous studies of head louse treatments and had expressed a wish to join further studies and were all female with ages ranging from 7-17 years (Table 2). Other demographic characteristics, such as hair color, length, and thickness, are also shown in Table 2. This product was delivered using the comb-like gel dispenser fitted to the bottle (Figure 4). We found that the application took between 4 and 10 min on children with hair of shoulder-length or longer. Six of the 10 participants were found to have fewer than 10 louse eggs or nits by combing with the others having 19, 25, 30, and 97 combed out and, on one participant (009), although eggshells could be seen pre-treatment, no eggs or nits were removed by the combing process, possibly because they were too shrunken by dehydration to be caught by the teeth of the comb (Table 3). Staining varied between individuals from $0 \%-100 \%$ of the eggs/nits, and those participants who had been treated to eliminate a head louse infestation within the previous 1-2 weeks generally showed poorer staining of eggs and nits (Table 3), but there was no single factor that could explain the variation in uptake of stain by the eggshells. 
Table 2. Field study of Paranix Eggs Locator Gel: Demographic characteristics of participants and time required to apply and wash off.

\begin{tabular}{|c|c|c|c|c|c|c|c|c|c|}
\hline \multirow{2}{*}{ Participant } & \multirow{2}{*}{ Age } & \multicolumn{5}{|c|}{ Hair Characteristics } & \multirow{2}{*}{$\begin{array}{l}\text { Scalp Skin } \\
\text { Color }\end{array}$} & \multicolumn{2}{|c|}{ Time in Minutes taken to } \\
\hline & & Length & Thickness & Curl & Type & Color & & Apply Gel & Wash Off Gel \\
\hline 001 & 17 & BS & M & S & G & $\mathrm{Br}$ & $\mathrm{W}$ & 4 & 4 \\
\hline 002 & 13 & BS & $\mathrm{F}$ & S & G & $\mathrm{B} / \mathrm{B}$ & $\mathrm{W}$ & 10 & 3 \\
\hline 003 & 10 & ES & $\mathrm{F}$ & $\mathrm{W}$ & $\mathrm{N}$ & $\mathrm{B} / \mathrm{B}$ & $\mathrm{W}$ & 10 & 5 \\
\hline 004 & 12 & BS & $\mathrm{F}$ & S & $\mathrm{N}$ & $\mathrm{Br}$ & $\mathrm{W}$ & 15 & 3 \\
\hline 005 & 10 & BS & $\mathrm{F}$ & $\mathrm{S}$ & $\mathrm{N}$ & $\mathrm{Br}$ & $\mathrm{W}$ & 8 & 4 \\
\hline 006 & 9 & BS & $\mathrm{T}$ & $\mathrm{S}$ & $\mathrm{N}$ & $\mathrm{Bl}$ & $\mathrm{W}$ & 5 & 4 \\
\hline 007 & 14 & BS & $\mathrm{T}$ & $\mathrm{C}$ & $\mathrm{N}$ & $\mathrm{Bk}$ & $\mathrm{W}$ & 5 & 3 \\
\hline 008 & 13 & BS & $\mathrm{T}$ & W & $\mathrm{N}$ & $\mathrm{Br}$ & W & 4 & 3 \\
\hline 009 & 9 & BS & $\mathrm{M}$ & $\mathrm{S}$ & $\mathrm{N}$ & $\mathrm{Br}$ & $\mathrm{W}$ & 5 & 5 \\
\hline 010 & 7 & ES & $M$ & $\mathrm{~S}$ & $\mathrm{~N}$ & $\mathrm{Br}$ & $\mathrm{W}$ & 8 & 2 \\
\hline
\end{tabular}

Key to hair characteristics. Hair length: BS = below shoulders, ES = ears to shoulders; hair thickness: $\mathrm{F}=$ fine, $\mathrm{M}=$ medium, $\mathrm{T}=$ thick; hair curl: $\mathrm{S}=$ straight, $\mathrm{W}=$ wavy, $\mathrm{C}=$ curly; hair type: $\mathrm{G}=$ greasy, $\mathrm{N}=$ normal; hair color: $\mathrm{Bl}=$ blonde, $\mathrm{Bk}=$ black, $\mathrm{Br}=$ brown, $\mathrm{B} / \mathrm{B}=$ brown-blonde; scalp skin color: $\mathrm{W}=$ white .

Table 3. Field study of Paranix Eggs Locator Gel: Effectiveness of staining of egg and nits, and scalp observations for staining.

\begin{tabular}{|c|c|c|c|c|c|c|c|c|c|}
\hline \multirow{3}{*}{ Participant } & \multicolumn{6}{|c|}{$\begin{array}{l}\text { Number of Eggs and Nits Removed by } \\
\text { Combing }\end{array}$} & \multicolumn{3}{|c|}{ Effects on the Scalp } \\
\hline & \multicolumn{2}{|c|}{ Unstained } & \multicolumn{2}{|c|}{ Stained } & \multirow{2}{*}{ Total } & \multirow{2}{*}{$\begin{array}{c}\% \\
\text { Stained }\end{array}$} & \multicolumn{2}{|c|}{ Staining Visible by } & \multirow{2}{*}{ Erythema } \\
\hline & Eggs & Nits & Eggs & Nits & & & Eye & Photography & \\
\hline 001 & 15 & 11 & 19 & 52 & 97 & $73.2 \%$ & No & No & No \\
\hline 002 & 3 & 2 & 8 & 17 & 30 & $83.3 \%$ & No & No & No \\
\hline 003 & 2 & 1 & 0 & 0 & 3 & $0.0 \% *$ & No & No & No \\
\hline 004 & 0 & 2 & 0 & 0 & 2 & $0.0 \%$ * & No & No & No \\
\hline 005 & 0 & 0 & 1 & 1 & 2 & $100.0 \%$ & No & No & No \\
\hline 006 & 0 & 0 & 1 & 1 & 2 & $100.0 \%$ & No & No & No \\
\hline 007 & 6 & 8 & 3 & 8 & 25 & $44.0 \%$ * & No & No & No \\
\hline 008 & 1 & 2 & 0 & 3 & 6 & $50.0 \%$ * & No & No & No \\
\hline 009 & 0 & 0 & 0 & 0 & 0 & $\mathrm{n} / \mathrm{a}$ & No & No & No \\
\hline 010 & 4 & 0 & 12 & 3 & 19 & $78.9 \%$ * & No & No & No \\
\hline
\end{tabular}

* Participants treated with a pediculicide within 1-2 weeks prior to using the egg detector gel.

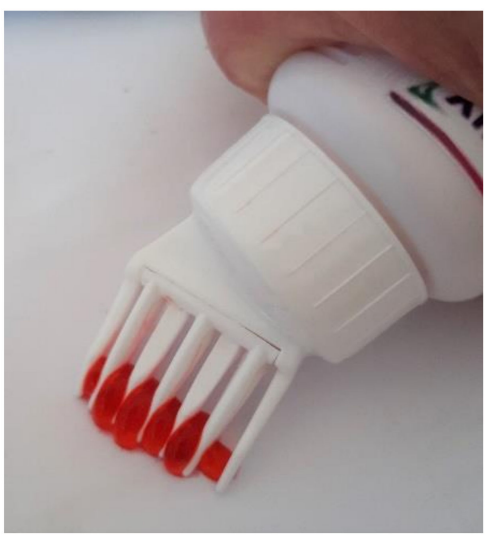

Figure 4. Comb-like dispenser fitted to the red dye gel bottle. 


\section{Discussion}

Removing louse eggs and nits is a practical problem faced by many parents, but finding them all poses an even greater problem. In countries like Britain, where the presence of old nits and eggshells is considered a cosmetic problem rather than an infestation risk to others, few people spend much time dealing with all nits unless their presence seriously affects the self-esteem of the child. However, in those places where complete removal of louse eggshells after treatment is considered an essential component of therapy, the so-called "no nit" policy concept, the problem can become insurmountable for some households. Consequently, one of the reasons that commercial "nit-picking" salons have become so successful in the USA and elsewhere is that, as a result of these "no-nit" policies, the professionals concerned have acquired a greater skill and are able to devote considerable time working through a head of hair, often strand by strand [16].

Nevertheless, many parents do choose to perform their own nit combing but are faced with the problem of knowing when to stop. Finding all eggshells among the hair strands is difficult, and reliably identifying eggs and nits among debris combed out can be difficult even for the experienced [17]. Development of a simple treatment making eggs and nits distinguishable from their background can make the task more straightforward and less stressful for children by reducing combing only to what is necessary. On heads with numerous louse eggshells, the difference identified in the Apaisyl study of $9 \%$ in the discovery of nits after use of the staining gel compared with the pre-treatment assessment was relatively minor but, on children with only a few eggshells, even such a small difference in detection could make the difference between success and failure to remove all nits. Such small differences in success can mean, for example, the difference between a child being readmitted to school after treatment and being re-excluded simply because one or two nits were found when a hygienist or school nurse re-examines the child's head for persistent signs of infestation. However, the results from both human studies showed that even in very different communities, the proportion of children with numerous nits persisting on their hair is low and that most have only a few eggshells at all stages of development, from recently laid through to old hatched nits. From the study point of view, this resulted in relatively low recovery rates of louse eggshells from most participants but overall was able to demonstrate that, provided there are no lingering residues of oily treatment products on the hair, the stains can help visualize persistent nits.

The value of a product of this nature may be questioned, but when the disruptive effects of "no-nit" policies on the functioning of schools, children's education, parents working, and the national economy are taken into consideration, any process that makes elimination of the signs of infestation easier and avoids rounds of unnecessary treatments and time off school, is a likely benefit. Despite advice from the U.S. Centers for Disease Control and Prevention [18], American Academy of Pediatrics [19], National Association of School Nurses [20], and state health services, many "no-nit" policies still operate in district schools in the USA. As a result, it has been estimated that up to 7 million unnecessary treatments for pediculosis are applied to children in North America simply because one or more louse eggshells persist on the hair after treatment and the professional examining the child was not able to distinguish these from viable louse eggs likely to lead to further infestation $[17,21,22]$.

This type of product does raise a regulatory conundrum. The majority of people using them do so for cosmetic reasons to remove the unsightly buildup of old eggshells that do not constitute an infestation risk. The Neon Nits $®$ Lice Egg Locator Spray product is sold as a cosmetic aid, and when the blue gel product was originally conceived for use in Spain, as stated in our introduction, it was only as a cosmetic aid. However, regulators in other countries did not agree, arguing that no user could be absolutely sure that no viable eggs were present on the scalp and on that basis they determined that is must be a diagnostic aid, which is why both the blue and red gels were registered as class I medical devices for use in the European Union.

Not surprisingly, the products we developed do not facilitate the physical detachment of louse eggs because they contain no components known to affect the grip characteristics of the louse egg fixative. Consequently, after using one of them, if eggs are missed by the combing process, they could 
be detected and removed at a follow-up examination because stained eggs retain color after treatment. Rinsing with water does not remove the color immediately, so it is possible to carry out the detection and combing process on more than one day to ensure all remaining eggshells have been removed. In addition, as a reassurance, the presence of the dye color on an eggshell confirms it is from past infestation rather than a newly laid egg. However, if desired, the color can be removed using a frequent wash shampoo.

Certain pediculicide treatments, such as those based on silicones, as well as oily hair treatments like olive oil, can reduce the binding of the dye to louse eggs and nits, although some staining does still occur (Table 3 and Figure 3b). Therefore, thorough shampooing to remove silicones or other oily residues before applying the gel makes staining more effective. It also helps the combing efficiency because any residual oil can allow some shrunken (dehydrated) eggs and nits to slip between the teeth of many of the combs sold to remove nits [7].

As the incidence of head louse infestation has not detectably diminished since the recent introduction of new pediculicides in Europe and North America, the need for additional aids to eliminate an infestation is no less than in past decades. Any preparation that helps families know whether they are reinfested regularly, or whether an infestation is simply persisting, could be of benefit in the long-term coping strategies required for dealing with lice. They can also be useful for professionals such as school nurses who need to make quick decisions about infestations that can have a social impact, either on the families concerned in terms of cost and time missed from school or work or else on the community if new infestations go untreated. A nit detection product can help distinguish between old treated cases and new infestations because newly laid eggs are unstained, indicating that treatment is required. However, stained eggs show they are not new and help to minimize exposure of children to unnecessary treatments [16,21], saving on cost, time, and any effects of exposure to pediculicides. This is a more pressing problem in countries where a nit detection product can help distinguish between old treated cases and new infestations because newly laid eggs are always unstained, indicating that treatment is required, such as in North America, where up until now, neither of these products has been marketed. In Europe, there is probably less concern about persistent nits overall, and, after several years of marketing, both products are currently listed at online pharmacies and other outlets in several countries as out of stock, with no restocking date.

Author Contributions: Conceptualization, E.R.B., I.P.W., and I.F.B.; Data curation, I.F.B.; Formal analysis, I.F.B.; Funding acquisition, I.F.B.; Investigation, E.R.B., M.N.B., and I.F.B.; Methodology, E.R.B., M.N.B., I.P.W., and I.F.B.; Project administration, E.R.B. and I.F.B.; Resources, E.R.B., M.N.B., I.P.W., and I.F.B.; Supervision, I.F.B.; Validation, I.P.W. and I.F.B.; Visualization, E.R.B. and M.N.B.; Writing-original draft, I.F.B.; Writing-review and editing, E.R.B., M.N.B., I.P.W., and I.F.B. All authors have read and agreed to the published version of the manuscript.

Funding: This research was funded by the following: The original blue nit stain gel project was proposed and supported in 2008-2009, see [11] by Laboratorios Cinfa S.A., Navarra, Spain, who later chose not to proceed for commercial reasons. The project was subsequently transferred and funded on a commercial product development basis by Merck Médication Familiale, Dijon, France in 2012, and the red nit stain gel by Omega Pharma N.V., Nazareth, Belgium.

Conflicts of Interest: The authors declare no conflict of interest. The development of these formulations was carried out on a commercial contractual basis between EctoMedica Limited and the funders. Insect Research \& Development Limited (IRD) is a contract research company conducting bioassay work on a commercial basis. The clinical investigation of the blue nit stain gel was conceived and designed by Merck Médication Familiale in collaboration with the independent consultant dermatologist at the Centre International de Développement Clinique on the island of Mauritius, with some advice and technical input from IRD. The clinical investigation of the red nit stain gel was designed and performed by IRD through its sister company, the Medical Entomology Centre, with no input from the funders in the design of the study, or in the collection, analyses or interpretation of data. None of the funders were involved in the writing of the manuscript, the collection analysis or interpretation of data, or in the decision to publish the results. 


\section{References}

1. Burgess, I. Malathion lotions for head lice-a less reliable treatment than commonly believed. Pharm J. 1991, 247, 630-632.

2. Meinking, T.L.; Entzel, P.; Villar, M.E.; Vicaria, M.; Lemard, G.A.; Porcelain, S.L. Comparative efficacy of treatments for pediculosis capitis infestations: Update 2000. Arch. Derm. 2001, 137, 287-292. [PubMed]

3. Combescot-Lang, C.; Vander Stichele, R.H.; Toubate, B.; Veirron, E.; Mumcuoglu, K.Y. Ex vivo effectiveness of French over-the-counter products against head lice (Pediculus humanus capitis De Geer, 1778). Parasitol Res. 2015, 114, 1779-1792. [CrossRef] [PubMed]

4. De Souza Bueno, V.; de Oliveira Garcia, L.; de Oliveira, N.J.; da Silva Ribeiro, D.C. Estudo comparativo da eficiência de três diferentes pentes finos na retirada de piolhos e lêndeas. Rev. Bras. Med. 2001, 58, 398-402.

5. Speare, R.; Canyon, D.V.; Cahill, C.; Thomas, G. Comparative efficacy of two nit combs in removing head lice (Pediculus humanus var. capitis) and their eggs. Int. J. Derm. 2007, 46, 1275-1278. [CrossRef] [PubMed]

6. Gallardo, A.; Toloza, A.; Vassena, C.; Picollo, M.I.; Mougabure-Cueto, G. Comparative efficacy of commercial combs in removing head lice (Pediculus humanus capitis) (Phthiraptera: Pediculidae). Parasitol. Res. 2013, 112, 1363-1366. [CrossRef] [PubMed]

7. Brunton, E.R.; Whelan, I.P.; French, R.; Burgess, M.N.; Burgess, I.F. Head louse egg and nit remover-a modern “Quest for the Holy Grail”. Peer J. 2019, 7, e6759. [CrossRef] [PubMed]

8. Burgess, I.F. Do nit removal formulations and other treatments loosen head louse eggs and nits from hair? Med. Vet. Entomol. 2010, 24, 55-61. [CrossRef] [PubMed]

9. Lapeere, H.; Brochez, L.; Verhaeghe, E.; Vander Stichele, R.; Remon, J.-P.; Lambert, J.; Leybaert, L. Efficacy of products to remove eggs of Pediculus humanus capitis (Phthiraptera: Pediculidea) from the human hair. J. Med. Entomol. 2014, 51, 400-407. [CrossRef] [PubMed]

10. Reid, L.F.; Kross, R.D. Method for Removing Nits from Hair. United States Patent 5,972,987, 26 October 1999.

11. Burgess, M.N.; Whelan, I.; Brunton, E.R.; Burgess, I.F. Making nit removal easier (poster). In Proceedings of the 4th International Conference on Phthiraptera, Urgup, Cappadocia, Turkey, 13-18 June 2010.

12. Burkhart, C.N.; Arbogast, J.; Smythe, P.; Burkhart, C.G. Histochemical analysis of the nit of Pediculus humanus capitis (Anoplura: Pediculidae). J. Med. Entomol. 1999, 36, 530-532. [CrossRef] [PubMed]

13. Burkhart, C.N.; Stankiewicz, B.A.; Pchalek, I.; Kruge, M.A.; Burkhart, C.G. Molecular composition of the louse sheath. J. Parasitol. 1999, 85, 559-561. [CrossRef] [PubMed]

14. McCann, D.; Barrett, A.; Cooper, A.; Crumpler, D.; Dalen, L.; Grimshaw, K.; Kitchin, E.; Lok, K.; Porteous, L.; Prince, E.; et al. Food additives and hyperactive behaviour in 3-year-old and 8/9-year-old children in the community: A randomised, double-blinded, placebo-controlled trial. Lancet 2007, 370, 1560-1567. [CrossRef]

15. Merck Médication Familiale. Evaluation of the efficacy of a nits revealing gel product. In Final Study Report, PRM03-F-077_A; Merck Médication Familiale: Dijon, France, 2012.

16. Shepherd, K. Lice Advice: The Shepherd Method ${ }^{\mathrm{TM}}$ of Strand by Strand Nit Removal; Stargroup International: West Palm Beach, FL, USA, 2009; p. 154.

17. Pollack, R.J.; Kiszewski, A.E.; Spielman, A. Overdiagnosis and consequent mismanagement of head louse infestations in North America. Pediatr. Infect. Dis. J. 2000, 8, 689-693. [CrossRef] [PubMed]

18. CDC. Head lice information for schools. Centers for Disease Control and Prevention. Available online: http://www.cdc.gov/parasites/lice/head/schools.html (accessed on 30 January 2020).

19. Devore, C.D.; Schutze, G.E. Head lice. Pediatrics 2015, 135, e1355-e1365. [CrossRef] [PubMed]

20. NASN. Pediculosis Management in the School Setting. National Association of School Nurses, Position Statement. Available online: https:/wvde.state.wv.us/healthyschools/section6/documents/ 2011NASNPediculosisPositionStatement.pdf (accessed on 30 January 2020).

21. Mumcuoglu, K.Y.; Meinking, T.L.; Burkhart, C.N.; Burkhart, C.G. Head louse infestations: The "no nit" policy and its consequences. Int. J. Derm. 2006, 45, 891-896. [CrossRef] [PubMed]

22. Williams, L.K.; Richert, A.; MacKenzie, W.; Hightower, A.W.; Blake, P.A. Lice, nits, and school policy. Pediatrics 2001, 107, 1011-1015. [CrossRef]

(C) 2020 by the authors. Licensee MDPI, Basel, Switzerland. This article is an open access article distributed under the terms and conditions of the Creative Commons Attribution (CC BY) license (http://creativecommons.org/licenses/by/4.0/). 